\title{
A De-Genderized English Language as A Model for Effective Extension Communication
}

\author{
Abdullahi, Al-Amin Adamu \\ NAERLS, Ahmadu Bello University, Zaria, Nigeria \\ Email: aaabdullahi2010@gmail.com.
}

\begin{abstract}
The division of the human race as reflected and indicated in English language is a semantic universal which is lexicalized in terms of pairs such as man - woman, boy - girl, son - daughter, and so on. This paper's investigation shows that English language is replete with sexist affixations, words, phrases and connotations which are denigrating and dehumanizing to the womenfolk. These are terms capable of making them inferior, invisible and irrelevant, and therefore impeding communication. The paper equally appraised the theoretical framework and ideological relations that rationalize such linguistic representation of women as little, substitute and gendered subjects. The paper concluded with a recommendation of a sociolinguistic model for the communicative use of English adaptable to extension communication.
\end{abstract}

Keywords: Extension communication, Degenderization, Sexism, Ideology, Linguistics.

\section{INTRODUCTION}

Communication is imperative to, and significant in determining the outcome of all extension activities and as such a methodical understanding of the communication process is essential for an effective and successful extension delivery. It is necessary, therefore, for all change agents to be good communicators. In this paper communication is seen as a process taking place between people: between extension agents and farmers or between extension workers and subject matter specialists, and so on. For the purpose of this paper, communication will be defined in agreement with Hanson (2005) as "the exchange of symbolic information that takes place between individuals who are aware of each other's direct or mediated presence". Therefore, the communication process must take cognizance of these individuals' sensibilities; the capacity to perceive and feel, and for emotional and aesthetic response to the code and content of communication, hence, gender sensitivity.

The concept of gender has influenced and guided much of feminist discourse since the 1960s. However, the modern meaning of gender can be located in Simone de Beauvoir's insight that "one is not born a woman, but becomes a woman" quoted in Robinson (1991). This assertion, in turn, takes its 
roots in cultural practices. This is why Eckert and Mcconnelt-Ginet (2003) observe that "gender is not an individual matter at all, but a collaborative affair that connects the individual to the social order". They further reason that "gender ideology is the set of beliefs that govern peoples' participation in the gender order and by which they explain and justify that participation" (Eckert and McconneltGinet (2003). It is this idea of participation that also implies gender differences. As Robinson (1991) rightly observes, recent studies in feminist theory have been replete with gender, race, class, and other cultural differences.

Thus, gender focuses on the means by which the individual becomes aware of his sex in terms of man or woman. It is this mechanism that produces placement and objectification in the system of social practices. In most patriarchal societies and indeed among farm population, women's oppression exists in the relations affecting the economic organization of households, the relations of production, the educational system, familial ideology, division of labour and cultural practice (manifesting in language use). As Barret cited in Webster (2007) has observed "the continuance and the entrenched nature of this oppression cannot be understood without a consideration of the cultural process in which women and men are represented differently, created and recreated as gendered human subjects". It is of interest that cultural practice (or difference) is often signaled grammatically in the language of extension communication. Interestingly, these grammatical features can have the effect of requiring individual speakers to signal not only the sex of people they address but also their own. For example, I am a happy farmer and you are a nice fellow.

In this paper, however, an aspect of linguistic differentiation that does not appear to be susceptible to the same kind of explication would be dealt with. This is because the relation between linguistic differentiation and cultural production raises the question of ideology. But then, what is the material process that influences and in some cases, structures the mental (or ideological) aspects of oppression via language. Some radical feminists have grounded the ideology of oppression in biology (Firestone in Webster, 1999) or present this ideology as self evident or self sustaining (Millet in Webster, 2006). This biological approach tends to abdicate the theory of representation as it purports to say that representation produces differences that cannot be known in advance. Bennet cited in Webster (2006) has shown that representation is necessarily a dialectical (or mediated) reflection of definite historical conditions. This indicates that sexism possesses some relation to the social relations of their production, and as the next sections show, is a potential impediment to extension communication.

\section{Linguistics, Ideology and (De)genderization.}

Linguistic pontification on degenderization of the English Language, though an old time favorite, predates the Chomskyan revolution in linguistics. This is true if the Sapir -Whorf's hypothesis that language influences our worldview is agreed on as setting the pace of the debate on gender. The import of their hypothesis is the idea that our attitude and perception in relation to others (in Freudian terms, the ' $l$ ' against the 'other') are viewed from the perspective of our language use. Sapir, for example, contends that "language is a symbolic guide to culture" 
(Abdulkadir, 2004). Whorf in Abdulkadir (2004), buttressed this view with the reinforcement that "language can transform our perception of the cosmos". $\mathrm{He}$ explains further that language habits are seen as determinant of social relation through their role in shaping the culture.

The following generation of linguistic experimentation with culture sort to support, modify or even out rightly reject the Sapir-Whorf hypothesis. Examples are Weggelar (1984) Sawin (1987), and Rosh (1987). It was Fisherman quoted in Inuwa (1994) who systematized the Sapir Whorfian hypothesis by delimiting the levels of interlingual and intralingual analysis of linguistic relativity. He said for example, that a level relates to the manner in which the presence or absence of some particular lexical or semantic phenomenon predicts the presence or absence of a certain kind of non linguistic response. Or that a level could demonstrate the grammatical phenomenon, purely lexical and semantic, which are shown to influence thought.

This elaborate analysis of the levels of linguistic relativity has been seen as a tacit endeavour on the degenderization project in English language. It is perhaps in this light that Martyna (1980) posits that the moderate version of the SapirWhorf hypothesis is reflected in the feminist movement for a non-sexist language. It was her argument that the issue is not what can be said about the sexes, but what can most easily and most clearly be said, given the constraints of the he/man approach.

Pursuing the same line of argument, Abdulkadir (2004) reports that Berstain held that the language a child learns affects what he learns, how it is learnt and sets limits on what future learning is possible. In his words, a number of fashions of speaking are possible in any given language and a number of fashions of speaking, linguistic forms, or codes, are themselves a function of the form social relations take. By this he meant that the form of the social relation, and by extension, the social structure, generates distinct linguistic forms or codes and these codes essentially transmit the culture and so constrain behavior.

Furthermore, this, in a sense, justifies Fox's (1981) presupposition that language habits must be learned which reflects the external reality of the speaker which is equally akin to the perception of reality as variable and constantly changing. Now, since thought is, by these postulates, becoming increasingly desexed in English as first language communities, the language which is the immediate actuality of thought is, by the same token, becoming desexed or degenderized.

\section{Various Manifestations of Sexism in English}

Any cursory look at English language from morphological, lexical to grammatical levels of linguistic analysis reveals a language with sexist connotations. Social inequality is a crucial factor to the cause of sexism in English Language which assumes the inherent superiority of men over the women folk. Inuwa (1994) has asserted that in British society, women are tied to the home, with very little variety of experience to divert their thoughts, and they dwell on 
misfortune in a way unknown and unsuspected by their more active partners (men).

\section{TABLE 1: Morphological, lexical and grammatical levels of manifestation}

\begin{tabular}{lll}
\hline \multicolumn{1}{c}{ Morphology } & \multicolumn{1}{c}{ Lexis } & \multicolumn{1}{c}{ Grammar } \\
\hline Man - mankind & Manpower - workforce & Generic terms - \\
& Manning - Staffing. & he, him and his. \\
Master - Master piece & Manmade -artificial & \\
Conductor - conductress & Man-hours - work hours & \\
Manager - Manageress & Man as suffix - band man & \\
Actor - actress & Statesman, pressman, & \\
Poet - Poetess & Fireman, hangman, & \\
Jockey - Jockette & Dustman, woman, chairman, \\
& etc & \\
\hline
\end{tabular}

Evaluation of column one in Table 1 readily testifies to sexual differentiation as it implies a second class status for women thereby rendering them invisible and inconsequential with regards to leadership role. The use of compounds like 'masterpiece' means that excellence is typically a male affair. Similarly, the use of feminine morphemes to masculine as in 'Manager/ Manageress', etc. equally discriminates by portraying women as inferior and incapable of professional skills, and trivial and therefore must be defined in relation to the man. This manner of speech puts the female folk off; detaches them from the extension agent, and as a result, the communication channel breaks down.

Column two contains discriminatory terms which unduly express male superiority and fermale insubordination. Occupational titles like cameraman, etc, give the feeling that a woman is subsumed and invisible and men are the only existing beings. In fact, any attempt to alter such morphological arrangement as in chairwoman, bandswoman, etc, will be declared ungrammatical and an oddity in English. The items are also capable of typifying women as objects or possession of men as Lakins in Webster (2006) has said "they are personal property of either fathers or husbands.

In the third column, the use of the masculine pronouns as generic - he, him and his to include female 'referents' is seen by feminist as signifying that experience is for men to the exclusion of women. Leland (1985) has argued that the generic 'his' is a sexist representation and a strategy to render the female irrelevant. Fasold (1990) concludes the debate when he said: "There has been substantial amount of research on masculine forms, and the results overwhelmingly support the conclusion that these uses have the effect of excluding women". The extension agent or subject matter specialist with this linguistic obsession cannot communicate effectively with women who today are known not only to own farm land but also manage and control hectares of land and farm machineries. 


\section{Gender Sensitive in English}

Gender sensitivity in English will avoid the use of lexical items which would label women as sex objects, subhuman or even a caricature. Therefore, the extension specialist and in indeed social communicators should desist from using such terms in reference to women in extension interaction: They include: peaches and cream, honey, sugar, kitten, a sow, a prune, a pickle, a click, a beetle axe, a pain, a doll, a dish, a nag, a pill, a bitch, a mosquito, etc. These terms describe the woman not as a human being but an animal, vegetable, fruit, mineral or any other inanimate objects, and can lead to hostility and hinder communication.

In addition, to be avoided also are terms which define the women folk in terms of their body, or part thereof, or as sex object. Examples are: a flirt, a hussy, a loose woman, hooker, tramp, whore, baggage, and in Nigerian parlance, area girl, or good-evening group. These terms are capable of breaking down the communication channel and may lead to hostility. As stated by Kleinman (2000), "there is a relationship between our language use and our social reality. If we "erase" women from language that makes it easier to maintain gender inequality".

So what should the extension agents do when faced with one of those gender-neutral or gender-ambiguous situations? Well, they have got a few options: for instance, use 'they' in situations where a pronoun needs to refer to a farmer whose gender isn't known; or write out both pronoun options as "she or he" or "she/he." They may also choose to alternate gendered pronouns. Alternatively, agricultural extension communicators may also make themselves clearer to the clientele by eliminating the pronouns altogether; for example, use chairperson instead of chairman, human beings for mankind, and machine made for man, to mention only a few.

\section{A Sociolinguistic Approach to Extension Communication}

The sociolinguistic perspective in the communicative use of English as applicable to extension communication embodies what this paper will regard as a "functional and interactional approach" to language use. The tendency in this approach is to supplement the narrow grammatical perspective restricted to phonology and syntax, with a focus on the analysis and usage of the pragmatic and communicative functions of English in extension communication.

The basic assumption which underlies this approach derives from reactions to the narrowness which hitherto has characterized language description; the reduction of the scope of 'language' to static formal descriptions of grammar is known to have excluded the procedural aspects of communication in extension interaction. Language, and by extension, communication can only be comprehended in the context of social behavior. The theoretical aim of this approach is the investigation of speakers' competence though in native speaker context, but applied in a non-native speaker context of English language usage. Its objective, therefore, should be to improve the communicative proficiency of the 
users of the language by exposing them to the functional varieties of the language which they may need in all extension communication interactions.

The sociolinguistic impetus in language and communication studies can be traced also to the distinction made by Ferdinand de Saussure cited in Hudson (1996), between what he termed "Langue" and "Parole". Langue being the selfcontained system of rules and pattern of a language while Parole describes the actual use of the language by the people to perform basically social functions. This distinction clearly suggests a sociological perspective from which language can be used. Hudson (1996) said Chomsky made, very much later, his own psychological distinction between "competence", the tacit knowledge which a native speaker possesses about their language, and "Performance" which refers to actual use of the language in real-life situations such as Extension. It can be said that sociolinguistics emerged from these initial attempts to distinguish and identify regular relationship between linguistic form and social function. Although certain functional roles of English in the two environments may be seemingly identical, the communicative effects of language use in such roles may be differently perceived depending on the differential interplay of cultural or social considerations. This does not mean, however, that such differing situations or contexts will still not entail considerable variation in linguistic forms which should be used as appropriate to the different contexts. These considerations need to be integrated into the English Language usage and strategies in extension communication.

A sociolinguistic model which is based on the concept of communicative competence is founded partly on a linguistic (that is, syntactic, semantic, and phonological) theory which incorporates appropriate social considerations and partly on a theory of speech and usage in appropriate situations. In this case, language elements such as sentences, phrases or words in English are not only correlated with non-linguistic elements such as status, rank, age, formality informality distinctions, but they are also seen as factors which determine as well as alter, the situational context of verbal interactions in extension provision.

The concept of communicative competence therefore describes the ability of individuals to communicate with one another under situational and normatively defined conditions which are linguistic; psychological, social and pragmatic in nature. Native speakers of a language are presumed to have internalized a system or systems of rules which govern the choice of appropriate varieties and their use, in the same way in which they have internalized the rules of grammar (Radford, 2004).

Second language users (- people learning any language other than mother tongue) on the other hand have a basic problem. Namely, although they may be able to acquire the systems of rules of grammar (grammatical competence), the acquisition of rules for use in terms of the choice of appropriate variety (communicative competence) is constrained by the fact that appropriateness is situation - bound. This is because socio-cultural differences do not allow for a one -on - one correspondence between the contexts or situations of language use in native-speaker environments and those of non-native environments, such as exist in the ethno-linguistic diversities of the multi-lingual Nigeria. 
By introducing the concept of 'communicative competence' Hymes in Radford (2004) seeks to expand the limits of linguistic theory by incorporating aspects of functional communication. Chomsky's postulates of grammatical competence (that is, the ideal speaker-hearer) definitely exclude social aspects of communication relevant to Extension delivery. In other words, sentences or utterances should not only be judged as grammatical or acceptable, but they must also be assessed by the extent to which they are used to effect actions or perform functions or relate to other people, etcetera, with what results or consequences.

\section{Implications of Language Use for Effective Extension Practice}

The sociolinguistic model of English usage in extension communication must include those aspects which in a theory of communicative competence should decide the way in which sentences or utterances of a particular syntactic structure, which are spoken with a particular intonation contour, are regarded as functional for a given situation. This is because some aspects of the functional variation which characterizes English usage show that some sentences which are identical in their formal grammatical structure can, according to the situational context, be interpreted as commands, requests, demands or apologies. By the same token, two grammatically different sentences can be understood as one and the same speech act. Interestingly, an extension of this sociolinguistic orientation is to see language use for such specific extension communication purposes as having some pragmatic consequences. For example, when an extension specialist makes a promise or apologizes for an action using appropriate verbal codes, she is performing an action which has some consequences both for herself and for others. Traditional grammatical categories are said to be inadequate for describing distinctions or variations of this kind.

There are moments in which the communicative interactions between the extension agents and farmers involve situations in which they use language to perform speech acts such as greeting, congratulating, thanking, offering condolences, apologizing, requesting, etcetera. The acquisition of some linguistic competence is necessary in order to be able to enact these speech acts. Therefore, there is need to distinguish, on the one hand, between sentence types as syntactic constructions whose interpretations are circumscribed by the conventional functions which have traditionally been ascribed to them. On the other hand, it is crucial to separate the syntactic variation which characterizes sentence types from their interpretation or use as speech acts which have specific communicative functions referred to as "illocutionary force". For example, the traditional sentence types in English are declarative, interrogative, imperative and exclamative which are said to make statements, ask questions, give commands and indicate exclamations, respectively.

Huddleston (1984) it was, who said "the illocutionary force of an utterance depends on a variety of contextual factors, viz, the beliefs, assumptions, intentions of speakers and addressees and their relative social statuses, which will not always be expressed in the grammatical structure of the sentence uttered". This goes to say that a sentence or an utterance, for example, which has an imperative 
structure (ie the absence of a subject noun phrase), can be used in an appropriate extension context to give a command or an instruction, express a wish, make a request, give an apology or offer an invitation, and so on and so forth. For example, the following imperative sentences have the illocutionary force of command, instruction and wish, respectively: get out of my farm; take a cup of water daily; and have a nice dry season. And these interrogative sentences will have the force of request and apology respectively: could you borrow me your hoe? and will you please accept my apology?. Similar instances are possible for the declarative, too. Indeed the declarative is seen to have a one - to - many relationship between it and its illocutionary force which makes it capable to function in speech acts as command, wish, apology, etc., as in "I invite you to attend my farm cultivation on Saturday; would you attend my farm cultivation on Saturday?; come to my farm cultivation on Saturday". These are respectively declarative, interrogative and imperative, functioning as invitations.

\section{CONCLUSION}

The trend in most recent sociolinguistic oriented studies of language use situations is to distinguish 'linguistic structure' from 'language usage'. The former is something that can be glossed as 'linguistic form and literal meanings (that is, grammar), and the latter as the employment of linguistic forms and literal meaning in particular contexts for particular extension communication purposes. The assumption here is that the successful management of inter-personal relationships is central for achieving individual communication goals in the context of extension delivery and social living. That is to say, the employment of appropriate linguistic forms can further enhance such relationships. This is why extension specialists who employ English language as vehicle for communication must be taught to incorporate those fine distinctions of usage that are both linguistically and socioculturally appropriate, into their speech repertoire.

\section{RECOMMENDATIONS}

1. Agricultural extension agents and their subject matter specialist counterparts with a one-to-one relationship with farm populations need to be encouraged to imbibe the principles of gender sensitive English.

2. The Agricultural Extension Society of Nigeria should make it a policy issue to advocate the inclusion into their curriculum of the degenderized English.

3. The paper wish to recommend the adoption of a sociolinguistics approach to communication in the practice of extension. 


\section{REFERENCE}

Abdulkadir, H N. (2004): Abuja Journal of English and Literary Studies. Vol. 1(1), pp. $132-144$.

Eckert P. and Sally McConnell-Ginet (2003). Language and Gender. Cambridge: Cambridge University Press.

Fasold, R. (1990). Sociolinguistics of Language. New York: Basil Blackwell.

Fox, W M (1981). "General Semantics as a Therapeutic Modality" Etcetera, vol. 39(1), pp. $76-83$.

Hanson, H E. (2005). Mass Communication Living in a Media World. New York: McGrow Hill.

Huddleston, R. (1984). An Introduction to the Grammar of English. Cambridge: University Press.

Hudson, R A. (1996). Sociolinguistics. Cambridge: Cambridge University Press.

Inuwa H M. (1994). Male Chauvinism: A Major Factor in the Manifestation of Sexism in Language. A seminar paper presentation in the Department of English and European Languages, Bayero University, Kano. pp. 3.

Kleinman, Sherryl (2000). The G-Word. Newsday, December 11th (A 35).

Leland R W. (1985). Correspondence on genderized language to editor. Etcetera, vol. 42 , pp. $406-407$.

Martyna, N. (1980). Beyond the he/man approach: the case for non-sexist language. SIGNS, vol.5, pp. $482-493$.

Radford, Andrew (2004). English syntax: an introduction. Cambridge: University Press.

Robinson, S. (1991). Engendering the subject: gender and self - representation in contemporary African fiction. Abbany: State University of New York.

Rosch E. (1987). Linguistic Relativity. Etcetera. Vol. 44, pp. 254 - 279.

Sawin G. (1987). Investigating the whorfian hypothesis. Etcetera, vol.44, pp. 293 294.

Webster, Juliet (2007). Editorial comment, special issue: Gender and ICT, Information Communication and Society, 2007, vol.10, pp. 279-286.

Webster, Juliet (1999). Technological work and women, prospects in the knowledge economy: an agenda for research. Information, Communication and Society, 1999, vol. 2, pp. 201-221.

Webster, Juliet (2006). Women in traditional and newly emerging jobs in the European service economy: working conditions, technology and corporate strategies, Labour and Industry. 2006, vol.16, pp. 59-72.

Weggelaar, C. (1984). "Whorf's hypothesis: the case of Dutch and English" In Morain. pp. $249-267$ 